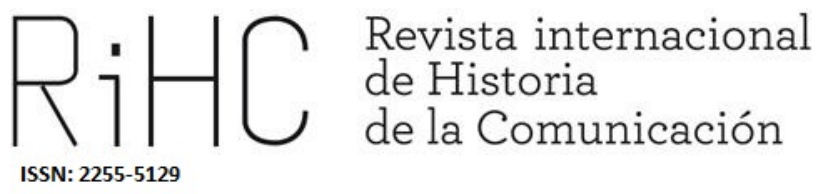

\title{
TENDER PUENTES, ACORTAR DISTANCIAS: PRENSA Y PERIODISTAS EN LA EMIGRACIÓN GALLEGA EN CUBA Y ARGENTINA
}

Build bridges, shorten distances: press and journalists in the galician emigration in Cuba and Argentina

DOI: http://dx.doi.org/10.12795/RiHC.2019.i12.06

Recibido: 04/03/2019

Aceptado: $14 / 05 / 2019$

Publicado: $15 / 06 / 2019$

Prudencio Viveiro Mogo

Consello da Cultura Galega, España

prudencio.viveiro@consellodacultura.gal

ORCID (i) 0000-0002-8417-5398

Como citar este artículo: VIVEIRO MOGO, Prudencio (2019): "Tender puentes, acortar distancias: prensa y periodistas en la emigración gallega en Cuba y Argentina", en: RIHC: Revista Internacional de Historia de la Comunicación, (12), pp. 107-133. 
Resumen: No se puede entender la Galicia contemporánea sin la influencia determinante de la emigración al continente americano, particularmente a Cuba y Argentina que fueron los destinos preferentes de los emigrantes gallegos. Los principales movimientos políticos, sociales y culturales buscaron en la emigración apoyos materiales y morales para conseguir sus objetivos. Por otra parte, todos estos movimientos tuvieron desde un principio su espejo en la emigración americana. En este juego de interrelaciones la prensa editada por los emigrantes en América jugó un papel determinante, pues permitió el conocimiento mutuo de ambas orillas del océano Atlántico. En el presente trabajo nos acercaremos a los principales hitos periodísticos gallegos en Argentina y Cuba, estudiando sus cabeceras más destacadas y a sus protagonistas. Todo ello con un objetivo: demostrar la cotidianidad de la emigración en la Galicia de la primera mitad del siglo XX, a lo que sin duda contribuyó de una forma muy relevante la prensa editada por los emigrantes, actuando de puente entre la Galicia europea y la Galicia emigrada.

Palabras clave: Galicia, emigración, prensa, Argentina, Cuba

\begin{abstract}
We can not understand the contemporary Galicia without the important influence of the emigration to the American continent, particularly to Cuba and Argentina that were the preferential destinations of the galician emigrants. The main political, social and cultural movements looked for in the emigration material and moral supports to achieve his aims. By another part, all these movements had from a principle his mirror in the American emigration. In this game of relationships the press edited by the emigrants in America played a important paper, this press allowed the mutual knowledge of both banks of the Atlantic ocean. In the present work, we will approach to the main important journals and journalists in Argentina and Cuba, approaching us to most important newspapers and jornalists. All this with an aim: we want to show the emigration like something usual in the Galicia of the first half of the century $X X$, to what no doubt contributed of a form very important the press edited by the emigrants, acting of bridge between the european Galicia and the Galicia emigrated.
\end{abstract}

Keywords: Galicia, emigration, Cuba, press, Argentina

\title{
Introducción
}

La influencia de la emigración en la historia contemporánea de Galicia es indudable. Los datos estadísticos básicos nos dan una idea de la magnitud del fenómeno. Entre 1835 y 1970 cerca de dos millones de gallegos y gallegas emigraron a América. Entre 1860 y 1970 los emigrantes gallegos representaron el 37,8 \% del total de salidas de españoles hacia el continente americano. Teniendo en cuenta que la población gallega en 1900 no llegaba al 11 \% de la española, la emigración gallega supuso el 2 \% de la emigración europea a América. Si nos centramos en los datos absolutos en la década 1921-1930 el número de gallegos emigrados fue de 290.500 , en ese mismo espacio temporal el porcentaje de la emigración gallega dentro del conjunto español era 
igualmente significativa: el 37,35 \% (Villares / Fernández, 1996: 35). Como nos recuerda Xosé M. Núñez Seixas, uno de los principales conocedores de la emigración gallega a América, en 1914 la ciudad en la que residían más gallegos era Buenos Aires, mientras que la segunda era La Habana, en tercer lugar, encontraríamos A Coruña y en cuarto Montevideo. En 1914 entre un 8 y un 10 por ciento de la población total de Buenos Aires era de origen gallego (Núñez Seixas 2010: 273). Son ejemplos bien significativos de la magnitud de la emigración gallega.

De esta forma, desde finales del siglo XIX, y sobre todo en las primeras décadas del siglo XX, miles de gallegos y gallegas emigraron a América, siendo Cuba y Argentina sus destinos preferentes. Los emigrantes desempeñaron una gran variedad de ocupaciones, destacando las relacionadas con el sector servicios. Menos comunes fueron, por el contrario, las vinculadas con las actividades intelectuales y culturales, en las que sin duda el periodismo ocupó un lugar preferente. Así, en el caso de los periodistas emigrados debemos hablar de una emigración cualificada que se compatibilizó en numerosas ocasiones con otras profesiones igualmente capacitadas, en las que destacó el ejercicio de la docencia.

Las remesas materiales de los emigrantes contribuyeron de forma significativa a transformar Galicia en el plano económico y social. Sin embargo, la aportación de los periodistas gallegos en la emigración nos acercaría además a las conocidas como remesas inmateriales, es decir, las ideas e influencias de los periódicos editados por estos periodistas emigrados (Núñez Seixas, 1998: 21).

En este trabajo nos acercaremos a la prensa producida en la emigración gallega en América, en sus dos destinos preferentes: Cuba y Argentina. Los periódicos editados en la emigración -junto con la edición de libros, tarea muy vinculada al periodismo emigrado- beben a un tiempo de las remesas materiales y de las inmateriales, pues si bien es cierto que hablamos de productos tangibles, también es verdad que los periódicos fueron vehículos de comunicación de nuevas ideas.

\section{Prensa y emigración gallega}

¿Cuál era el papel de la prensa editada por los emigrantes gallegos? En primer lugar, obviamente, mantener informada a la colonia gallega. Informada en un doble sentido: por una parte, de la vida social de la colectividad; y por otra, recibir noticias actualizadas de Galicia. Estas dos secciones se repetían en la mayoría de los periódicos de la emigración. Ahora bien, en segundo lugar, la difusión de la prensa emigrada trascendía a las propias colectividades que la producían. La prensa, como los emigrantes, viajaba con asiduidad a través del océano Atlántico. Los periódicos y 
revistas editados en Buenos Aires y La Habana eran consumidos también en la tierra natal, lo que contribuía también a que en Galicia se tuviera una noticia actualizada de la labor de los emigrantes. Es decir, salvando las enormes distancias, la prensa gallega en la emigración contribuyó de una forma notable al conocimiento mutuo y a la continua ósmosis de las dos Galicias: la europea y la emigrante. En las primeras décadas del siglo XX la emigración formó parte de la cotidianidad de Galicia. Una normalidad a la que, sin duda, también contribuyó la interrelación favorecida por la prensa emigrada (Villares, 2017: 73).

La prensa de la emigración gallega tuvo unos perfiles literarios muy marcados. Perfil que solía expresarse en lengua gallega con frecuencia. En este sentido, las principales plumas de la Galicia de comienzos del siglo XX, la mayoría de los escritores gallegos del momento, colaboraron con los periódicos de la emigración. Lo que, por supuesto, era visto con total normalidad. Formaba parte del paisaje de la época (Villares, 1997: 211).

Los periodistas gallegos de la emigración podemos ubicarlos en un plano diferente al de la mayoría de los emigrantes. Nos situamos en una emigración cualificada que, frente a los oficios vinculados al sector terciario que desempeñaron la gran parte de los emigrantes gallegos, sus ocupaciones tendrán un perfil cultural, literario o académico. Los periodistas gallegos en Buenos Aires y en La Habana ejercieron una intermediación positiva entre la colectividad gallega emigrada y las autoridades de los países de acogida, lo que les permitió también un ascenso social como líderes étnicos (Núñez Seixas, 2010: 275-276). En este sentido, los directores y promotores de los periódicos gallegos en la emigración vendrían a jugar un papel muy similar al que ejercieron los presidentes de las sociedades gallegas en Cuba y Argentina.

Por lo que se refiere al estado de la cuestión en los estudios de la prensa gallega en la emigración contamos con algunas investigaciones dedicadas al recuento exhaustivo del número de publicaciones. En este sentido es de destacar el libro dirigido en 1998 por Vicente Peña Saavedra Repertorio da prensa galega na emigración, promovido por el Arquivo da Emigración del Consello da Cultura Galega. Con el mismo componente genérico debemos señalar el libro de Xosé Luís Blanco Campaña Prensa e radio na Galicia exterior, publicado en 1995 por la Xunta de Galicia. Para el caso cubano, es muy relevante el estudio de Xosé Neira Vilas $A$ prensa galega en Cuba, publicado originalmente en 1985 y reeditado en 2011 por la Xunta de Galicia. En general, la obra ensayística de Neira Vilas es muy recomendable para un acercamiento a la emigración gallega en Cuba. Para el conocimiento de los más relevantes periodistas gallegos en la Argentina debemos recurrir a la obra, en dos volúmenes, de Alberto Vilanova Rodríguez Los gallegos en la Argentina, publicada en 1966 por el Centro Gallego de Buenos Aires. Finalmente, un repertorio amplio de la prensa gallega, que incluye también las publicaciones periódicas de la emigración, podemos encontrarlo en el libro 
de Enrique Santos Gayoso Historia de la Prensa Gallega, publicado originalmente en 1990 y con varias ediciones posteriores.

Finalmente, en cuanto a la consulta de la prensa editada por los gallegos en América, como en general en lo referente a la prensa histórica, la progresiva digitalización y consiguiente consulta en Internet ha facilitado el acercamiento a estas fuentes. Debemos señalar sobre todo el portal "Galiciana»" ${ }^{1}$, de la Xunta de Galicia. Por esta misma línea, el "Centro Ramón Piñeiro para a Investigación en Humanidades» ha publicado facsímiles de periódicos de la emigración gallega, que también se pueden consultar en la Red ${ }^{2}$. De la misma forma, el Consello da Cultura Galega dispone en su página web de un "Repertorio da prensa da emigración galega», que, al tiempo que ofrece información de los periódicos y revistas de la emigración, permite la consulta de muchas de ellas ${ }^{3}$.

\section{Prensa y periodistas gallegos en la Argentina}

Si bien es cierto que la inmensa mayoría de los emigrantes gallegos que llegan a la Argentina procedían de las áreas rurales del interior y de la costa, también es necesario destacar una emigración más cualificada, con una formación previa, que les permitió desarrollar en el país austral tareas intelectuales. En este grupo es donde debemos situar a los periodistas gallegos en la Argentina, dentro de los cuales podemos diferenciar dos generaciones. Una primera fase en la que predominaron los desterrados con motivo del fracaso de la Primera República española. Republicanismo, regeneracionismo, regionalismo y el deseo de contribuir a elevar el buen nombre de Galicia serían sus características principales. Una segunda generación, que llegó a la Argentina a finales del siglo XIX, compartió principios ideológicos e intenciones con la primera oleada, añadiendo ahora la defensa y promoción de la educación como factor de progreso para Galicia (Núñez Seixas, 2010: 276-277). En el presente epígrafe nos ocuparemos de dos representantes de la primera generación (César Cisneros Luces y Manuel Castro López) y otros dos de la segunda (Fortunato Cruces Angueira y José Ramón Lence).

\footnotetext{
${ }^{1}$ http://www.galiciana.bibliotecadegalicia.xunta.es

${ }^{2}$ https://www.cirp.es/w3/publicacions/

${ }^{3}$ http://consellodacultura.gal/fondos_documentais/hemeroteca/coleccion.php?id=406
} 


\subsection{Cesar Cisneros Luces y El Gallego}

El nacimiento de la prensa gallega en la Argentina podemos fecharlo en 1879 con la aparición de El Gallego. Su creador, César Cisneros Luces, era poseedor de un importante bagaje periodístico, adquirido en la emigración cubana y uruguaya. El Gallego nació como órgano oficioso del primer Centro Gallego de Buenos Aires, del cual Cisneros Luces fue promotor y primer vicepresidente. El periódico sufrió los avatares del Centro Gallego, desapareciendo en noviembre de 1880.

César Cisneros Luces fue uno de los principales representantes del periodismo emigrado, actuando tanto en Cuba como en Argentina. Nació en Muros (A Coruña) el 22 de septiembre de 1849. Tras cursar los estudios primarios, con trece años emigró a La Habana, ciudad en la que residía su tío Andrés María Cisneros Pereira. Comenzó a trabajar como dependiente de comercio, al tiempo que mejoraba su formación cultural. De esta época proceden algunas colaboraciones en el periódico habanero Diario de la Marina. Se trasladó con su tío a Cárdenas y más tarde a Sagua la Grande, siendo en esta última localidad director del periódico La Voz de Sagua. Los problemas de salud le obligan a retornar a Galicia en 1868. Tras su regreso ejerció como docente en la Escuela Naval flotante de aprendices de mar, instalada en la corveta "Mazarredo" en el Arsenal de Ferrol. Su oposición a la sublevación republicana del 11 de octubre de 1872 motivó su captura por los sublevados. Cisneros Luces narraría posteriormente estos hechos en el libro La insurrección del Ferrol. En 1873 volvió a seguir el camino de la emigración, esta vez hacia el Río de la Plata. Se asentó en un primer momento en Uruguay. Cofundador del colegio "Hispanoamericano" de enseñanza primaria en la localidad de La Unión, tiempo después pasó a ejercer la administración de una oficina del Ferrocarril Central uruguayo. En el Uruguay también se dedicó al periodismo, siendo director de La Carta Blanca, periódico desde el cual combatió la dictadura de Lorenzo Latorre. Las persecuciones políticas motivaron su marcha a Buenos Aires en abril de 1877.

Así, el 15 de mayo de 1877 comenzó a trabajar en El Correo Español. César Cisneros Luces fue uno de los promotores, el 13 de marzo de 1879, de una convocatoria de la que saldría el primer Centro Gallego de Buenos Aires, siendo elegido como vicepresidente de la primera junta directiva de esta institución. Debemos señalar que Cisneros Luces mantuvo muy malas relaciones con Manuel Vázquez Castro, a la sazón presidente del Centro Gallego, diferencias que al parecer estarían en el origen de la desaparición de la propia entidad. Desde las columnas de El Gallego, cuyo primer número ve la luz el 27 de abril de 1879, Cisneros Luces criticó duramente la gestión de Vázquez Castro ${ }^{4}$.

\footnotetext{
${ }^{4}$ Manuel Vázquez Castro (1844-1885), más conocido por el pseudónimo periodístico de Manuel Barros, para defenderse de las críticas que desde las páginas de El Gallego le digiría Cisneros Luces, creó la publicación decenal Revista Galaica, cuyo primer número apareció el 10 de octubre de 1879; de breve
} 
El primer número de El Gallego apareció el 27 de abril de 1879, llevando por subtítulo "Periódico semanal, órgano de los intereses de su nombre». En su primer ejemplar podía leerse un programa eminentemente regenerador, defendiendo el progreso y el bienestar de Galicia. Sus promotores veían el Centro Gallego como un instrumento de los emigrantes en Buenos Aires en el camino de esa deseada regeneración. Para sus promotores, El Gallego debía contribuir a la unión de los naturales de Galicia en Buenos Aires; pero no solo, esa unión era parte de una entente mayor, aquella que reunía a todos los gallegos, independientemente de su residencia. Así, el periódico pretendía servir de puente entre la tierra natal y los emigrados:

La unión hace la fuerza y ya que este aforismo se aplica con frecuente abuso á la satisfacción de personales ambiciones, probemos una vez por todas que somos dignos del país que nos vió nacer, haciendo por él, por nuestro nombre en estas playas lo que hacen actualmente en todas partes nuestros hermanos de causa: unámonos y seremos fuertes, conocidos y respetados.

El pacto social gallego debe atravesar los mares y tomarnos a nosotros en una de sus más vigorosas y fecundas ramificaciones.

Tras la desaparición de El Gallego, cuyo último número sale el 7 de noviembre de 1880, Cisneros pasó a trabajar como corrector de pruebas en El Diario. También trabajó como inspector de desembarque, dentro del Departamento general de Inmigración. En enero de 1883 daría comienzo una segunda época de El Gallego, que, sin embargo, solo conseguiría sobrevivir seis meses. No obstante, en mayo de 1888 Cisneros promovería una tercera época de este periódico, que sería igual de breve que las dos anteriores. Su siguiente trabajo fue como corrector de pruebas en el diario Sudamérica. Fundó después La Bandera Española, que solo publicó siete números.

Finalmente, se trasladó a Montevideo, donde pasó a colaborar con numerosas cabeceras, algunas de las cuales: El Pampero, La Unión Gallega, Montevideo Noticioso y también en la capital Oriental existió un periódico titulado El Gallego. En noviembre de 1896 enfermó y fue internado en el hospital italiano de Montevideo. Al salir de este sanatorio regresó a Buenos Aires, donde al poco de llegar tuvo que ser nuevamente internado en el Hospital Español, centro en el que falleció el 4 de enero de 1897 (Vilanova Rodríguez, 1966, tomo II: 862).

duración, su último número salío el 10 de junio de 1880. Vázquez Castro fue también el fundador del diario La Nación Española (1881-1883), en este medio Rosalía de Castro publicó los poemas que más tarde reuniría en el libro En las orillas del Sar (1884), muestra evidente de la cercanía que propiciaba la prensa editada por los gallegos en Buenos Aires (Vilanova Rodríguez, 1966, tomo II: 811).

${ }^{5}$ El Gallego, Buenos Aires, 27 de abril de 1879. 


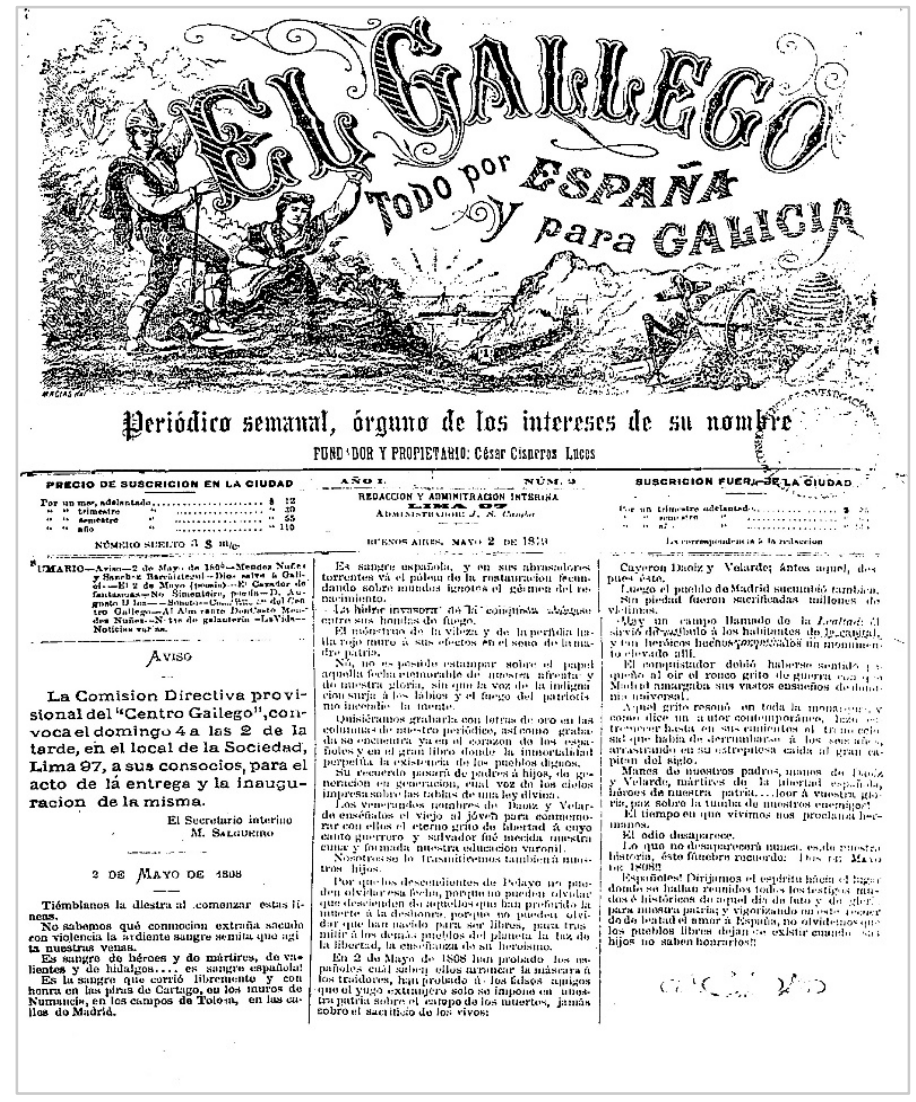

Imagen I: El Gallego (Buenos Aires). Fuente: Galiciana

\subsection{Manuel Castro López y El Eco de Galicia}

El lucense Manuel Castro López (1860-1926) fue otro de los puntales de la prensa gallega en Buenos Aires. A él se deben dos productos periodísticos indispensables para conocer la emigración gallega en la Argentina. Por una parte, la publicación anual del Almanaque Gallego, obra que vio la luz durante veintinueve años ininterrumpidos (1898-1927). La aparición de los volúmenes del Almanaque Gallego contribuyó a acercar a los gallegos de dos continentes, los que permanecían en Galicia y los que emigraran a Buenos Aires. En las páginas de esta publicación, además de los textos del propio Castro López, colaboraron las principales plumas gallegas del momento (Barreiro Fernández, 2012: 30-31). Ya en el primer volumen, Castro López reforzaba la idea del papel del Almanaque Gallego como mediador entre los gallegos de Galicia y los que residían en Argentina:

Emprendemos la publicación de este Almanaque, el primero gallego en América, con un fin noble y determinante del progreso: el de ampliar la obra a cuya realización viene aspirando EL ECO DE GALICIA de dar a conocer en las repúblicas 
del Plata a la pequeña patria, y en la pequeña patria el saber, el ingenio y la honrosa acción de sus hijos residentes en estos países ${ }^{6}$.

En este sentido, la misión de este producto periodístico era la misma que la fijada para la prensa editada en la emigración, es decir, favorecer el acercamiento y acortar las distancias entre la Galicia europea y la Galicia emigrada. La otra aportación de Castro López a la prensa de la emigración fue la dirección del periódico El Eco de Galicia, diario que, si bien no fundó, sí que consiguió imprimirle su particular estilo de dirección.

La biografía de Castro López está plenamente vinculada al mundo de las letras. En su ciudad natal (Lugo) realizó sus estudios, comenzado a trabajar en las oficinas del Juzgado de Primera Instancia. En esta ocupación adquirió la categoría de oficial mayor, siendo posteriormente habilitado para el ejercicio de una escribanía adscrita al Juzgado. Políticamente se vinculó al republicanismo federal ligado a Francisco Pi i Margall. En este sentido, Castro López fue secretario de la asamblea federal celebrada en Lugo en 1887, reunión en la que se redactó un anteproyecto de Constitución para el futuro Estado gallego. En 1889 fundó en Lugo el periódico El Ciudadano, este semanario sintetizaba el pensamiento de Castro López: republicano, masón y anticlerical. Es también por esta época en la que da a la imprenta sus primeras obras: Hijos distinguidos de la provincia de Lugo (Lugo, 1890), Efemérides galaicas (Lugo, 1891) y La Asociación de Escritores y Artistas de Lugo (Lugo, 1891). Con anterioridad publicó en A Coruña su obra Los jesuitas al desnudo (1887), donde daba muestras de su acendrado anticlericalismo.

Su actividad política está íntimamente vinculada a su decisión de emigrar. Sin ir más lejos, la presión del obispo de Lugo sobre los impresores de la ciudad motivó el cierre del semanario dirigido por Castro López El Ciudadano. En efecto, la presión de los poderes oficiales de la Restauración canovista motivaron que Castro López decidiera seguir el camino de la emigración a Buenos Aires, ciudad a la que llegó el 10 de mayo de 1892. Sin embargo, en su decisión de emigrar también habría influido el enfriamiento de sus relaciones con otros dos periodistas lucenses: Manuel Amor Meilán y Aureliano Pereira (Barreiro Fernández, 2012: 17-18). Comprobamos que Manuel Castro López no era un emigrante común, empujado a emigrar por necesidades económicas. Estamos ante una emigración (¿exilio?) de tipo cultural e intelectual. El ejercicio de un periodismo subversivo lo llevó a Buenos Aires, ciudad donde continuará desempeñando su profesión.

En la capital argentina comenzó a colaborar en El Eco de Galicia, semanario fundado por el también lucense José Cao Luaces (1862-1918), hombre muy ligado al mundo de

\footnotetext{
${ }^{6}$ Almanaque Gallego para 1898, Buenos Aires, ano I, Imprenta y Encuadernación El Correo Español, 1898, p. 3.
} 
la cultura gallega en la Argentina y que conseguiría una importante fama como caricaturista. El primer número de El Eco de Galicia salió de la imprenta el 7 de febrero de 1892. El artículo publicado por Cao Luaces en este primer ejemplar demostraba claramente el talante regionalista del semanario:

Galicia es nuestro lema y teniendo por divisa el sacrosanto nombre fuente de todas nuestras energías iVive Dios que no trepidaremos en desplegar la bandera! (...) No debemos renegar jamás del nombre glorioso que simboliza el pabellón ibero, pero si estamos dispuestos a sostener que si hubo algún pueblo en la tierra con derecho a ser regionalista, a romper la centralización política y administrativa del Estado, ese pueblo ha sido el gallego? ${ }^{7}$

No obstante, los anhelos de Cao Luaces no se vieron cumplidos. No hubo una respuesta decidida por parte de la colectividad gallega en Buenos Aires. Al fracasar una reunión en la que se pretendía reconstituir el Centro Gallego, Cao Luaces en las columnas de El Eco de Galicia cargó contra esta apatía. No fueron bien recibidos estos artículos y muchos comerciantes comenzaron a anular las suscripciones al semanario. Cansado de estas luchas, en octubre de 1892 Cao Luaces cede a Manuel Castro López la dirección del semanario El Eco de Galicia.

Para evitar problemas, Castro López dio al periódico un tono mucho menos político, sin por ello abandonar la reivindicación de Galicia. Hizo campaña regionalista sin citar el regionalismo. Defendió la descentralización y realizó una apología de los valores gallegos, todo con el objetivo de aumentar la autoestima entre los gallegos emigrados (Beramendi, 2007: 331). Esta nueva línea editorial fue del gusto de los lectores, que volvieron a acoger con satisfacción el semanario. En la idea de favorecer la comunicación con la tierra natal, Castro López introdujo información de Galicia en las columnas de El Eco de Galicia, de esta forma podemos comprobar como la prensa gallega en la emigración actuó de mediadora entre los gallegos de las dos orillas del océano. Así, a lo largo de 34 años, Castro López dirigió El Eco de Galicia hasta su muerte.

\footnotetext{
${ }^{7}$ El Eco de Galicia, Buenos Aires, 7 de febrero de 1892.
} 


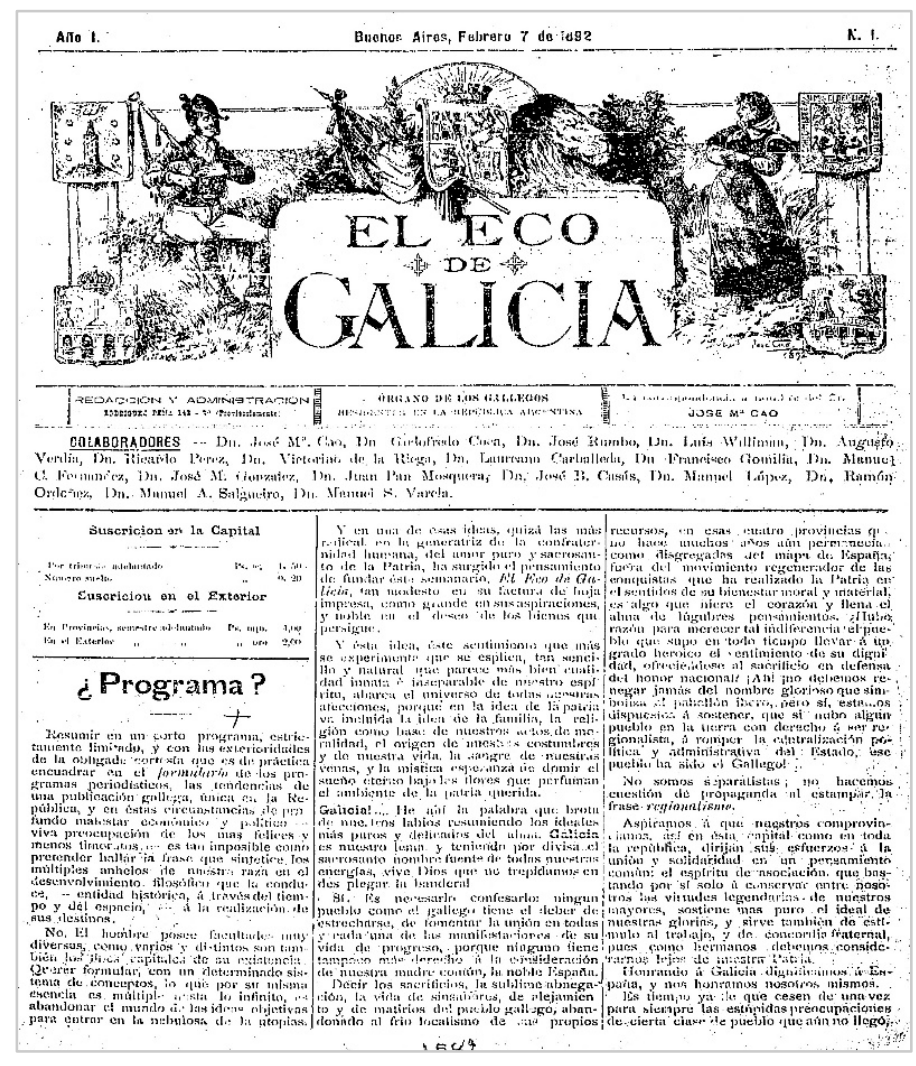

Imagen II: El Eco de Galicia (Buenos Aires). Fuente: Galiciana

\subsection{Fortunato Cruces y Nova Galicia}

Fortunato Cruces Angueira nació en el municipio de Dodro (A Coruña) el 11 de junio de 1870. En 1885 emigró a la Argentina, asentándose en la localidad de Rosario; aquí, además de ejercer diversos oficios comerciales y periodísticos, adquirió una notable formación, la cual le permitió entrar a trabajar en el despacho de un notario de Buenos Aires. En esta ciudad, tras completar su formación, trabajó como procurador. En el barrio de Barracas al Norte fundó el semanario La Justicia, al tiempo que colaboraba en diversos medios de la colectividad gallega de Buenos Aires. Así, en 1893 dirigió la revista El Río Sar y en 1898 participó en la fundación de un primer Correo de Galicia.

En 1901 fundó Nova Galicia, cuyo primer número vio la luz el 6 de octubre de ese año. El periódico fue uno de los de más larga duración de la emigración gallega -si bien con periodos de interrupción en la década de los años 30 del siglo XX- pues pervivió hasta 1951 (Núñez Seixas, 2010: 279-280). En mayo de 1914 comenzó una nueva aventura periodística: el diario vespertino La Colonia Gallega que, sin embargo, tan solo logró sobrevivir algunos números. A diferencia de otros periodistas gallegos en Buenos Aires -caso de José Ramón Lence-Cruces no desarrolló un pensamiento político elaborado, manteniéndose siempre en posturas folklorizantes, apelando a la morriña de los emigrantes. En este sentido, las publicaciones de Cruces $-y$ en particular en caso de 
Nova Galicia- estaban destinadas a alimentar la morriña de los gallegos residentes en Buenos Aires. Significativos eran los versos que acompañaban, número tras número, la cabecera de Nova Galicia:

\author{
Nunca, galleguiños, nunca, \\ olvidemos nosa terra, \\ amor, sospiros, recordos, \\ teñamos sempre por ela. \\ Esta folla ten d'ouxeto \\ sempre á Galicia alabar, \\ e con noticias e contos \\ aos seus fillos alegrar.
}

Podemos describir Nova Galicia como un periódico de información general dirigido a los gallegos emigrados. El objetivo de dignificar Galicia y su cultura se concretaba en artículos sobre lengua, literatura, costumbres, historia o música. Para mantener informados a los emigrantes disponía de secciones con noticias de Galicia, bajo los rótulos de "Novedás d-a nasa terra» o "Novedades do noso chan». Por otra parte, existía una sección dedicada a la actualidad de la colonia gallega ("Cousas d'acá»), sobre todo en lo que se refiere a la actividad de las numerosas sociedades gallegas de Buenos Aires. En este sentido, Nova Galicia, y en general la prensa de la emigración gallega, desempeñó un destacado papel en la promoción del asociacionismo étnico, favoreciendo la creación de sociedades y dando publicidad a sus actividades, ya fueran recreativas, mutualistas o los trabajos llevados a cabo por estas entidades en Galicia (Núñez Seixas, 2014: 432-433).

La dedicación de Fortunato Cruces a las letras en la emigración bonaerense no se limitó solo al periodismo. En efecto, este autor también tuvo un papel destacado en la edición del libro gallego en la capital argentina, dando a la imprenta obras como: Primeiras follas: contos e copras (1898), Almanaque de Galicia (1909), Castañolas. Contos, cartas, descursos, cantares e outras cousas (1913) o Cousas gallegas (1923) (Vilanova Rodríguez, 1966, tomo II: 1.178). Fortunato Cruces falleció en Buenos Aires en 1961. 


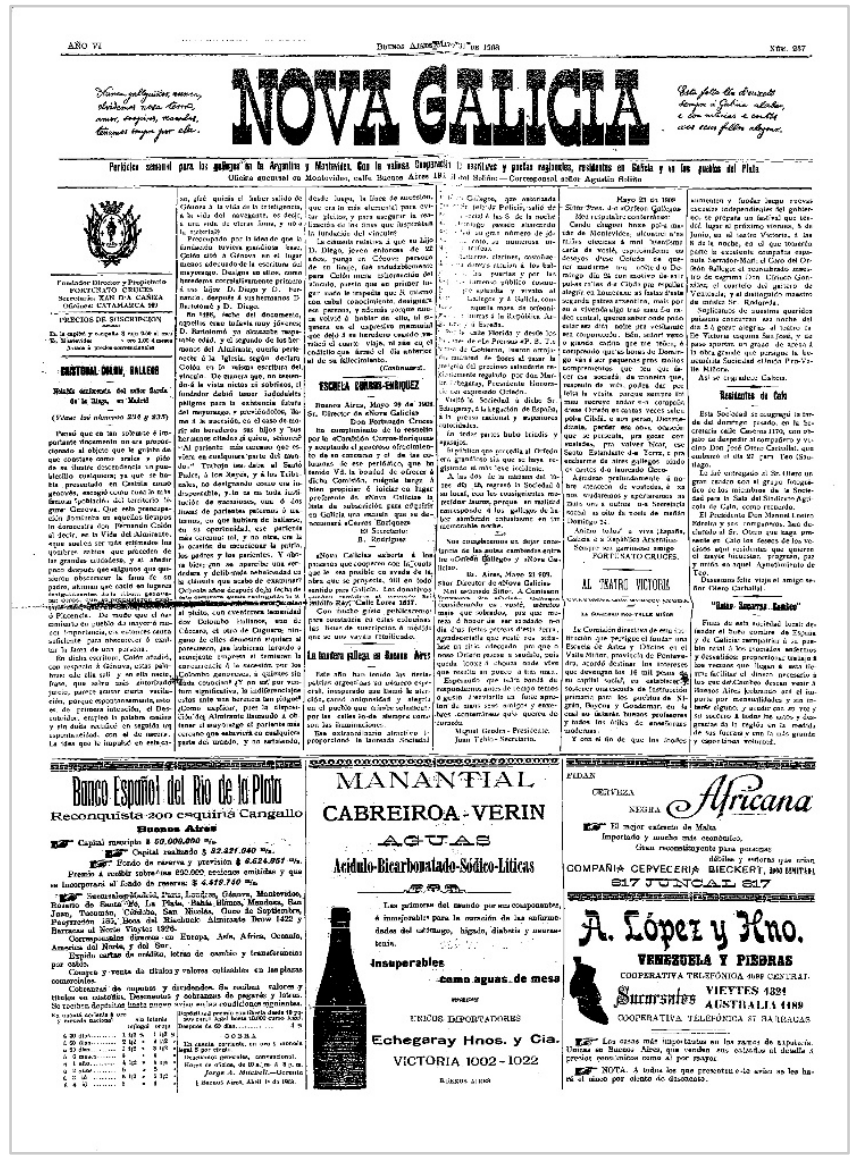

\subsection{José Ramón Lence y Correo de Galicia}

José Ramón Lence nació el 16 de octubre de 1874 en A Coruña. Realizó sus estudios en el colegio de los escolapios en Monforte de Lemos (Lugo), localidad donde también comenzó sus relaciones con el periodismo. De esta forma, colaboró en medios como $\mathrm{El}$ Eco y Heraldo de Monforte, llegando a dirigir el periódico maurista La Opinión. La imposibilidad de ascender en los empleos públicos que compaginaba con el ejercicio del periodismo motivó su decisión de emigrar. En efecto, Montevideo sería en 1903 el primer destino de Lence, donde trabajó como redactor del periódico La Democracia. En abril de 1905 se trasladó a Buenos Aires, entrando en la redacción de El Diario Español, medio fundado por el periodista Justo López de Gomara. Fue precisamente en las columnas de este medio, en noviembre de 1906, en las que José Ramón Lence propuso la refundación del Centro Gallego de Buenos Aires, campaña que se coronó con éxito y que permitió a Lence adquirir un notable protagonismo entre la colonia gallega. Debemos señalar también sus colaboraciones en los periódicos El Diario y La Argentina (Vilanova Rodríguez, 1966, tomo II: 1.207).

Junto a varios socios, entre los que podemos destacar al también periodista gallego José Vázquez Romaguera, fundó el semanario Correo de Galicia, cuyo primer número 
apareció el 22 de marzo de 1908, perviviendo bajo la dirección de Lence hasta 1945, año en que modifica su nombre por Nuevo Correo. Si bien Nova Galicia fue el periódico de más larga duración, podemos afirmar que Correo de Galicia fue el medio de más difusión e influencia entre la colonia gallega de Buenos Aires. Al igual que Fortunato Cruces, el periodista Lence pretendió reforzar los lazos de unión y solidaridad entre los gallegos emigrados, para lo cual favoreció la creación de sociedades gallegas en Buenos Aires, entidades que tenían como objetivo la defensa de las causas de Galicia en la capital argentina. Tanto Cruces como Lence actuaron como intermediadores entre la colonia gallega y las autoridades (tanto argentinas como españolas) (Núñez Seixas, 2010: 281). Este papel de mediadores, de puente necesario, es el que venimos destacando como principal objetivo de la prensa en la emigración gallega. Sin embargo, Lence tuvo una importante evolución ideológica. En sus inicios se adscribió al regionalismo de cariz regeneracionista propio de los periódicos gallegos de Buenos Aires de finales del siglo XIX, mantuvo un breve idilio con el nacionalismo gallego y desde las páginas de Correo de Galicia se opuso a la Dictadura de Primo de Rivera. Manifestó un progresivo desapego hacía el régimen de la Segunda República española, lo que le llevó en 1936 a apoyar la causa de la sublevación franquista, situación que lo aisló dentro de una colectividad gallega mayoritariamente partidaria del régimen republicano. Pero, más allá de estos vaivenes, José Ramón Lence hizo de Galicia y de su dignificación una bandera a lo largo de los años. Tal y como podemos leer en el primer número de Correo de Galicia:

Pretendemos que CORREO DE GALICIA sea el fiel exponente de la cultura y aspiraciones de nuestro país, aquí donde es fuerza confesar que aún se nos conoce a través de una falsa leyenda que la ignorancia popular se ha encargado de ir propagando con una constancia digna de mejor causa, y abrigamos la plena convicción de que con una labor seria y continuada en este sentido se desvanecerán muchos errores y el nombre de nuestra amada Galicia será pronunciado con el respeto a que por tantos títulos tiene derecho ${ }^{8}$.

Era Correo de Galicia una publicación de información general, en sus páginas ocupaba un lugar destacado la información de las instituciones de los emigrantes en Buenos Aires. Estas noticias se completaban con notas de sociedad, biografías de personajes relevantes, información consular y, en general, aquello que se pensaba de utilidad para el emigrante. Incluía también noticias de la actualidad de Galicia ("Información Regional» o «De interés Regional»). En este sentido, contenía colaboraciones sobre la realidad cultural y literaria de la Galicia del momento.

Al igual que Fortunato Cruces, Lence desarrolló en Buenos Aires una fructífera carrera literaria, la cual debemos entender también como un medio para "educar" a los emigrantes en el amor a Galicia y la solidaridad. Y que mejor género literario que el

\footnotetext{
${ }^{8}$ Correo de Galicia, Buenos Aires, 22 de marzo de 1908.
} 
teatro para llegar a un gran público. Veamos algunos ejemplos de obras de José Ramón Lence. En 1914, conjuntamente con Ramón Fernández Mato, estrenó la zarzuela La Galleguita, en que trataba el tema del retorno de los emigrantes a Galicia. Otras obras suyas fueron La Conquista de América (1914), Rosiña de Belesar, El Almacenero, Gente de Casa (1915) y Luz de Aurora (1917). (Núñez Seixas, 2010: 279). Debemos mencionar también sus obras de carácter memorialístico Jornadas de lucha (1924) y Memorias de un periodista (1945). José Ramón Lence falleció en Buenos Aires el 19 de enero de 1951.

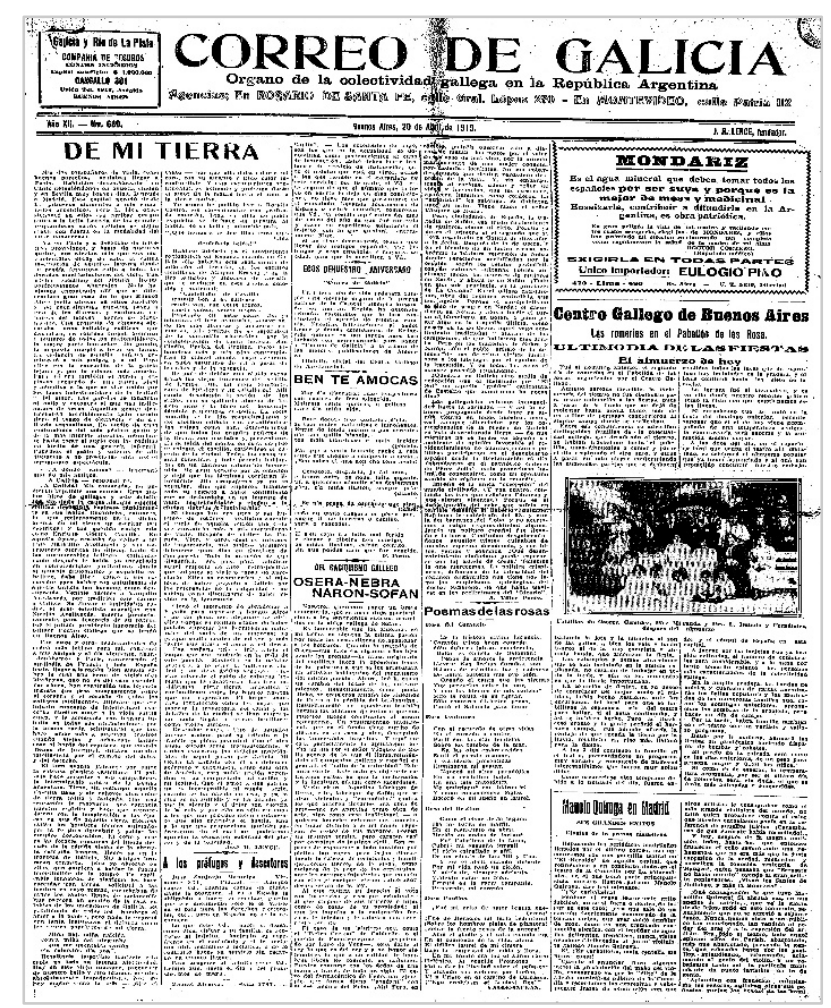

\subsection{Prensa oficial de la colectividad gallega en Buenos Aires}

No podemos finalizar el epígrafe de la prensa gallega en la Argentina sin mencionar la que podríamos considerar como prensa oficial de la colectividad gallega ${ }^{9}$. Si en algo

\footnotetext{
${ }^{9}$ En la nómina de grandes periodistas gallegos en la Argentina debemos citar a Joaquín Pesqueira Quiroga, director de la revista Suevia, publicada en Buenos Aires en dos épocas (1913 y 1916). Pesqueira tuvo también un notable protagonismo en la prensa argentina, siendo redactor del diario La Nación. Curiosamente, en La Habana exisitió una revista Suevia que se publicó en dos épocas diferentes. La primera en 1910, durando hasta 1912, bajo la dirección de Ricardo Carballal; revista semanal ilustrada, con un carácter netamente literario, aunque también informaba de las actividades de las sociedades gallegas. La segunda, con breve duración en 1916, bajo el impulso del periodista Jesús Peynó Piñeiro (1869-1948), contó con la colaboración de Ricardo Carballal (Blanco Campaña, 1995: 102).
} 
destacó la emigración gallega en América fue por desarrollar una nutrida red de sociedades que, al tiempo que sirvieron para la solidaridad comunitaria, ayudaron a hacer realidad los anhelos colectivos. Estas sociedades también crearon sus propios periódicos, empezando por las grandes instituciones mutualistas gallegas en Buenos Aires. Desde julio de 1907 el Centro Gallego contó con un primer medio de comunicación denominado Región Galaica. Mientras que desde enero de 1913 el órgano de la institución fue el Boletín Oficial del Centro Gallego, que desde 1926 cambió su nombre por Galicia.

La Federación de Sociedades Gallegas Agrarias y Culturales de la República Argentina (FSG, creada en 1921) contó desde 1922 con un medio de expresión propio: la revista El Despertar Gallego, que en 1930 cambiaría su nombre por Galicia ${ }^{10}$. Al mencionar estas publicaciones debemos recordar la figura de Antón Alonso Ríos (1887-1980), fundador y primer director de El Despertar Gallego. Figura central de la colectividad gallega en Buenos Aires durante el primer tercio del siglo XX. Alonso Ríos fue un destacado líder del agrarismo, tanto en la emigración argentina como en la Galicia republicana. Ese perfil agrarista se trasladaría a las páginas de las revistas de la FSG, especialmente El Despertar Gallego, que llego a tirar 15.000 ejemplares, una cantidad importante de los cuales llegaba a la propia Galicia. La amplia difusión de este periódico en Galicia constituye un ejemplo de la voluntad intervencionista de la FSG en la política gallega, al tiempo que nos muestra el papel capital de la prensa como vehículo de comunicación e influencia de los emigrantes (Núñez Seixas, 1998: 288). El Despertar Gallego fue clave para la difusión de los ideales de la FSG entre la colectividad emigrada, hasta tal punto que, según el investigador Hernán M. Díaz, publicación y Federación llegaron a confundirse: «Como se ha dicho más de una vez, es tan cierto que la Federación creó El Depertar Gallego como afirmar que fue el periódico el que creó la Federación» (Díaz, 2007: 23).

De igual modo, las pequeñas sociedades de ámbito municipal o comarcal contaron con sus propias publicaciones. En este sentido, y a título de ejemplo significativo, podemos mencionar la revista Alborada, órgano de la Asociación Benéfica y Cultural del Partido de Corcubión (A Coruña), que vio la luz en 1925 y que continúa a publicarse en la actualidad.

Si uno de los hilos conductores de este trabajo es el papel de la prensa como mediadora entre ambas orillas del océano, no podemos finalizar el resumen de la prensa gallega en la Argentina sin mencionar el relevante papel desempeñado por la revista quincenal Céltiga, editada en Buenos Aires entre septiembre de 1924 y julio de

\footnotetext{
${ }^{10}$ Es necesario no confudir esta entidad con una primitiva Federación de Sociedades Gallegas creada en 1910 por seis sociedades. La principal promotora de este primer proyecto federativo fue la Unión Hispano Américana "Valle Miñor". La tentativa de unión terminó, sin embargo, en fracaso (Núñez Seixas, 1998: 255-256).
} 
1932. La creación de esta revista fue fruto del encuentro de militantes republicanos como Domingo Rial Seijo o Ramón Peña con notorios galleguistas como Eduardo Blanco Amor, Fernando Lorenzo Rico o Ramón Suárez Picallo. En efecto, por lo que a los galleguistas se refiere, la creación de esta revista debemos enmarcarla dentro de una estrategia política más posibilista y práctica que la llevada hasta aquel momento por la «Irmandade Nazonalista Galega (ING)» de Buenos Aires. Los promotores de Céltiga buscaban crear una publicación de cultura y política que destacase por su calidad. En base a la popularidad que la revista alcanzó, tanto en la emigración como en la propia Galicia, podemos decir que lo consiguieron. Situamos, pues, a Céltiga como órgano estratégico para construir una República federal en España y un régimen de autonomía para Galicia (Viveiro Mogo, 2010: 397-400). El objetivo mediador era señalado por la revista en la hora de su nacimiento:

"CÉltigA", en las actividades que inicia, llega al campo periodístico dispuesta a volcar todas sus energías en el crisol de la mayor y más perfecta compenetración entre los gallegos de aquende y allende el mar, entre las colectividades hispánicas radicadas, y entre todos con los pueblos sudamericanos. Del conocimiento de Galicia por la Argentina, y de ésta por Galicia, haremos el mejor y más grato postulado ${ }^{11}$.

\section{Prensa y periodistas gallegos en Cuba}

En el último tercio del siglo XIX la prensa gallega tenía un gran desarrollo en Cuba, ya que en aquella época la isla de Cuba era la principal receptora de emigrantes gallegos. Si seguimos las informaciones suministradas por Xosé Neira Vilas, que fue sin duda uno de los mayores conocedores de la labor de los emigrantes gallegos en Cuba, el periódico gallego más antiguo editado en la isla caribeña fue La Gaita Gallega, semanario que se publicó en la Habana entre el 7 de enero y el 11 de febrero de 1872. Por otra parte, en Cienfuegos aparecería, entre el 3 de febrero y el 2 de noviembre de 1878, el semanario El Avisador Galaico. Para Neira Vilas estas cabeceras constituyen la prehistoria de prensa gallega en la isla de Cuba (Neira Vilas, 2011: 11).

Sin embargo, la presencia de gallegos en la prensa de Cuba venía de más atrás. En efecto, el gallego Isidoro Araujo de Lira (1816-1861) participó en 1844 en la creación del periódico Diario de la Marina. Este medio, que nacía de la fusión de dos diarios anteriores, acabaría por convertirse en el principal periódico de Cuba hasta el triunfo de la Revolución cubana, que lo incautó en 1960. Pocos casos existen tan notorios de vinculación de un diario y un país como el ejemplo del Diario de la Marina y Cuba.

\footnotetext{
${ }^{11}$ Céltiga, Buenos Aires, no 1, 30 de septiembre de 1924.
} 
Desde su creación hasta su abrupto cierre este periódico recorrió la vida contemporánea de la Cuba colonial y de la Cuba independiente, siempre desde una perspectiva conservadora y oligárquica. Si bien es cierto que entre finales del siglo XIX y hasta su desaparición este diario permaneció en manos de la familia Rivero, es necesario destacar que en su creación y en sus primeros años de vida tuvo un destacado protagonismo Isidoro Araujo de Lira, personaje principal a quien sin duda podemos situar como precedente de los grandes hitos del periodismo gallego en la emigración americana (Bugallal, 1959: 10).

También fue en La Habana donde se creó el primer periódico escrito íntegramente en lengua gallega. Nos referimos a A Gaita Gallega, cuyo primer número se publicó el 5 de julio de 1885 , sobreviviendo hasta $1889^{12}$. Este periódico, que salía mensualmente, fue fundado por dos grandes dinamizadores de la vida cultural gallega en la capital de Cuba: Manuel Lugrís Freire (1863-1940) y Ramón Armada Teijeiro (1858-1920). Las colaboraciones de estos dos periodistas impregnaron completamente A Gaita Gallega, medio que llevaba por subtítulo «Repenica Muiñeiras, Alboradas e Fandangos unha vez ó mes». En sus páginas Armada Teijeiro empleaba el pseudónimo de "Chumín de Céltigos», mientras que Lugrís Freire firmaba como «Roque d’as Mariñas». Sería precisamente este segundo quien redactó el editorial -bajo el título de «O noso pensamento»- del primer número de $A$ Gaita Gallega, en el podemos comprobar como el principal objetivo de la publicación era contribuir desde Cuba al renacimiento de la lengua gallega, sin por eso sacar conclusiones políticas, ya que el periódico tuvo un carácter literario (Regueiro, 2006: 45-104). En cualquier caso, este medio es una prueba más de lo cerca que la emigración vivía los movimientos culturales que se desarrollaban en Galicia:

Nosoutros que adouramos â nosa terra con verdadeiro amore; nosoutros, os gallegos de Cuba que siguimos c'o cariño d'un bô fillo todol-os xeitos que tom'a rexeneración d'a pátrea; nosoutros non podemos por menos qu'axudar, c'o qu'as nosas pequenas forzas poidan, á erguer d'a deixadez en que por longo tempo estivo, a dociña fala d'os nosos abôs ${ }^{13}$.

\subsection{Waldo Álvarez Insua y El Eco de Galicia}

El 8 de marzo de 1878 apareció en la Habana el primer número de El Eco de Galicia de la mano de Waldo Álvarez Insua (1856-1938). Por su difusión, por su prolongación en

\footnotetext{
${ }^{12}$ Téngase en cuenta que la primera publicación periódica escrita íntegramente en gallego en Galicia apareció solamente nueve años antes. Se trataba de $O$ Tío Marcos d'a Portela, fundado en Ourense por Valentín Lamas Carvajal en 1876.

${ }^{13}$ A Gaita Gallega, Tocata Primeira, 5 de julio de 1885.
} 
el tiempo (se publicó hasta 1902) y por la influencia que consiguió, no solo en La Habana, también en la misma Galicia, podemos afirmar que El Eco de Galicia fue el primer periódico de la emigración gallega. Pensado como un medio de información general, incluía artículos de temática variada sobre Galicia, prestando especial interés a las noticias de las sociedades fundadas por los gallegos de Cuba (Peña Saavedra (dir.), 1998: 205-206). Este periódico ejerció una notable influencia en la colonia gallega de La Habana. Así, a título de ejemplo, podemos anotar que fue en sus páginas donde el propio Álvarez Insua propuso la creación de una gran sociedad que uniera a los gallegos de la capital de Cuba. La propuesta tuvo éxito y esa entidad sería el Centro Gallego de La Habana creado en 1879 (Neira Vilas, 1994: 19).

Waldo Álvarez Insua nació en A Estrada (Pontevedra) el 10 de junio de 1856. Los artículos publicados en El Diario de Santiago, en los que criticaba el sistema político de la Restauración, le ocasionaron serias dificultades que están en el origen de su decisión de seguir el camino de la emigración, decisión que también se vio favorecida por la proximidad de tener que cumplir con el servicio militar (Arca Caldas, 1997: 11-12). Caso análogo al de otros periodistas gallegos como el ya comentado de Manuel Castro López. Tras llegar en 1877 a Cuba realizó estudios de Derecho en la Universidad de La Habana, abriendo posteriormente bufete de abogado.

Sin embargo, fue el ejercicio del periodismo lo que dio más visibilidad a Waldo Álvarez Insua. En 1878 funda el semanario El Eco de Galicia, medio desde el cual sería uno de los principales propagadores del Regionalismo gallego en Cuba, sin por ello dejar de ser un firme defensor de la españolidad de la isla (Beramendi, 2007: 329). Desde las páginas de El Eco de Galicia Álvarez Insua emprendió varias campañas en defensa de la colonia gallega. Una de las más conocidas se desarrolló en 1879, criticando la intención de los principales hacendados cubanos de sustituir la mano de obra esclava por inmigrantes gallegos. A través de las columnas de su semanario Álvarez Insua se convirtió en un hábil polemista, participando en las principales discusiones que afectaban a la colectividad gallega de La Habana, sobre todo en lo relacionado con la administración del Centro Gallego.

Además de abogado y periodista Álvarez Insua fue un relevante escritor. En 1889 publicó Galicia contemporánea: (páginas de un viaje), fruto de su visita a Galicia un año antes, obra publicada bajo el sello de "La Propaganda Literaria», que dirigía en La Habana el también gallego Alejandro Chao. En 1891 publicó en A Coruña Ecos de mi Patria, recopilación de artículos que tienen a Galicia y a grandes personajes gallegos como centro. En 1897 publicó en Madrid el libro El Problema Cubano, volumen en el que Álvarez Insua reflexiona sobre un tema de candente actualidad: la guerra de independencia de Cuba.

En 1898 abandonó la dirección de El Eco de Galicia -que no obstante se seguiría publicando-y regresó a Galicia. Asentado en un primer momento en A Coruña, en esta 
ciudad fue elegido como presidente de la Liga Gallega, principal entidad regionalista de Galicia, colaborando frecuentemente en la Revista Gallega, órgano de expresión de la Liga. En noviembre de 1899 se traslada a Madrid, ciudad en la que ejerció la abogacía y el periodismo. En la capital de España Álvarez Insua continuó como propagandista de los intereses gallegos, participando en la constitución del Centro Gallego. Tampoco olvidó su actividad como escritor. En 1901 salió de la imprenta su novela Finis. Últimos días de España en Cuba. Otras novelas suyas fueron: Deseada (1910) y El Milagro (1912). Waldo Álvarez Insua falleció en Madrid el 10 de agosto de 1938 (Arca Caldas, 1997: 39).

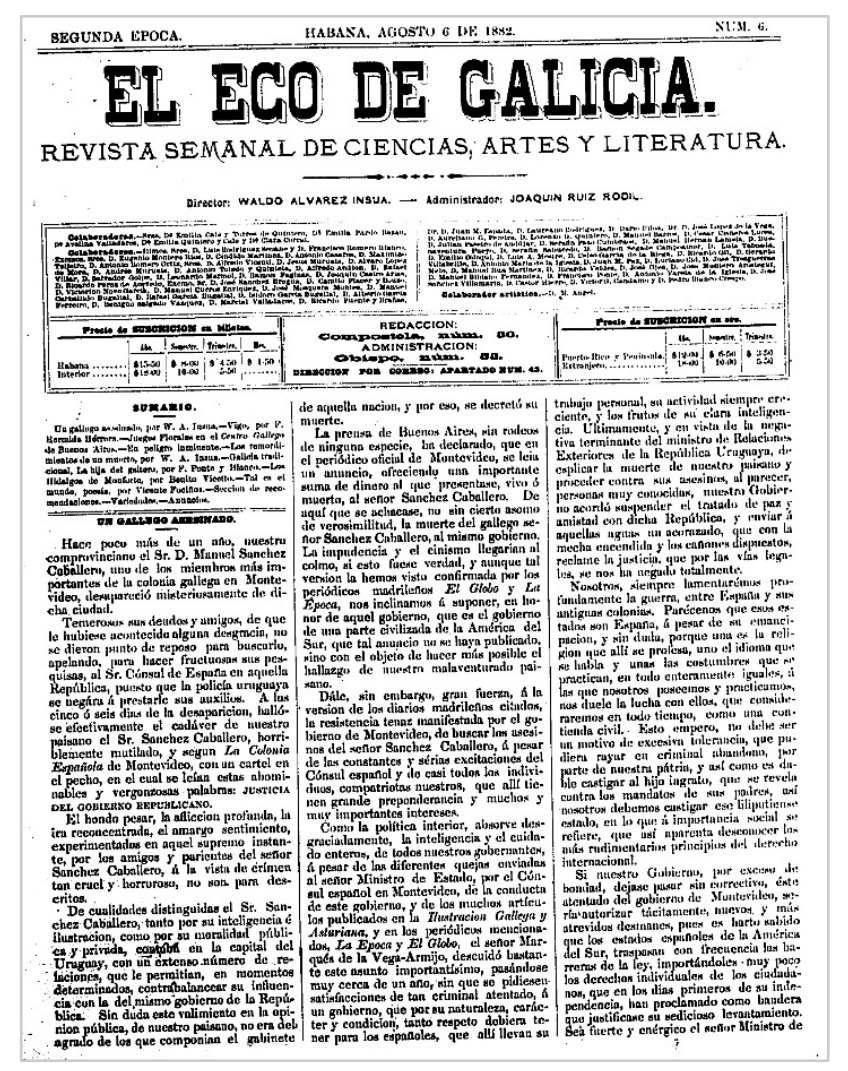

\subsection{Otros periodistas gallegos en La Habana}

A pesar de su relevancia, El Eco de Galicia no fue el único periódico con el que contaron los gallegos emigrados en La Habana. En efecto, igual importancia tuvo el semanario Follas Novas, que se publicó en La Habana entre junio de 1897 y septiembre de $1908^{14}$. Fundado por Antonio de P. Cea y J. Raimil. Periódico de información general, con una destacada presencia de la actividad de las sociedades gallegas de La

\footnotetext{
${ }^{14}$ Este semanario tomaba su nombre del libro de poemas de Rosalía de Castro Follas Novas (1880), obra capital del Rexurdimento gallego, curiosamente se publicó bajo la edición de la empresa «La Propaganda Literaria», que dirigía en La Habana Alejandro Chao.
} 
Habana. Las noticias culturales e históricas ocupaban un papel relevante en sus páginas. Un aspecto destacado de este semanario fue la publicación de obras literarias por entregas, algo muy común en la prensa del siglo XIX. De esta forma, podemos destacar la publicación en Follas Novas de dos novelas en lengua gallega. En 1897 vio la luz en este semanario A campaña da Caprecórneca, obra del escritor y militar Luis Otero Pimentel (1834-1920). También por entregas, entre 1899 y 1900, apareció iA Besta!, obra de Xan de Masma, pseudónimo literario de Patricio Delgado Luaces (18501900). La novela de folletín fue uno de los principales productos culturales del siglo XIX, también presente en la prensa de la emigración gallega de La Habana. Una muestra más de la importancia que tuvo la emigración para la historia contemporánea de Galicia (Peña Saavedra, 1998: 206-207).

El poeta Manuel Curros Enríquez (1851-1908), uno de los puntales del Rexurdimento literario gallego, emigró a La Habana en 1894. Casi desde su llegada se puso al frente del periódico La Tierra Gallega, medio que vio la luz el 1 de abril de 1894, sobreviviendo hasta abril de 1896. En este semanario tenemos otro ejemplo de prensa generalista gallega en La Habana. En sus columnas se prestaba atención a la actividad de la colonia gallega, especialmente al Centro Gallego y a la Sociedad de Beneficencia de Naturales de Galicia. Las noticias de Galicia, agrupadas en la sección «Las cuatro hermanas» también tenían una importante presencia. La historia de Galicia, las colaboraciones literarias y el folletín ocupaban el resto del semanario. Tras la desaparición de La Tierra Gallega, Curros Enríquez pasó a trabajar en otros medios de la prensa habanera, sobre todo en el Diario de la Marina, principal diario cubano de la época ${ }^{15}$.

Para finalizar la nómina de los principales periodistas gallegos emigrados en La Habana debemos referirnos a Adelardo Novo Brocas (1880-1939), director de El Diario Español, medio de comunicación creado en 1907. Adelardo Novo era miembro de una importante familia de periodistas forjados en la emigración. En este sentido son de estacar sus tíos José y Enrique Novo García, responsables del semanario Galicia Moderna, publicado en La Habana entre 1885 y 1890.

\footnotetext{
${ }^{15}$ En 1915 aparecería en La Habana un semanario también denominado La Tierra Gallega, dirigido por el periodista emigrado Roberto Blanco Torres (1891-1936). Emigrado a Cuba en 1906, tras su regreso a Galicia en 1916 Blanco Torres trabajó en los principales diarios de Galicia, como por ejemplo La Zarpa (Ourense), Galicia (Vigo) o El Noroeste (A Coruña). Su compromiso con el régimen de la II República motivó su asesinato en los primeros días de la Guerra Civil.
} 


\subsection{Manuel Fernández Doallo y la Empresa de Publicidad Galiciana}

También en Cuba se fundaron empresas dedicadas a la edición de libros y periódicos. Podemos destacar, en este sentido, la figura de Manuel Fernández Doallo, quien fundó y dirigió en La Habana la Empresa de Publicidad Galiciana.

Natural de Ourense, Manuel Fernández Doallo fue el fundador de dos importantes cabeceras de prensa en La Habana: Eco de Galicia y Heraldo de Galicia, propiedad ambas de su Empresa de Publicidad Galiciana. Como insistimos en este trabajo, la importancia de estas dos publicaciones periódicas estriba en su papel de puente entre la Galicia europea y la emigrada, que reducía las distancias y favorecía el conocimiento de ambas.

Eco de Galicia, cuyo primer número aparece en 1917, fue una de las revistas más populares entre la colectividad gallega emigrada en Cuba. En general, la publicación abordaba temas históricos, geográficos, económicos, folklóricos y literarios. En sus páginas encontraron eco los principales movimientos sociales actuantes en la Galicia del momento, tales como el agrarismo y el nacionalismo. Insertaba semblanzas de las principales personalidades gallegas, así como una sección de efemérides. Proporcionaba también una crónica de actualidad de Galicia y de las sociedades gallegas de La Habana, así como de las colectividades emigradas en otros países de América. El idioma gallego tenía una importante presencia en Eco de Galicia, tanto en prosa como en verso. Hasta 1919 Fermín Méndez Álvarez fue el administrador de la revista. Desde este último año J. Otero Pérez ocupó el cargo de jefe de redacción, quien en 1922 fue substituido por Antonio do Campo.

En 1919 Fernández Doallo fundó Heraldo de Galicia, semanario bilingüe en formato tabloide, que se publicó con regularidad durante catorce años. El semanario llevaba por subtítulo «Periódico Consagrado a los Intereses del Pueblo Galiciano y Paladín de la Colonia Gallega de Cuba». Trataba críticamente los problemas de Galicia. Informaba sobre la actualidad gallega y de la emigración. Destacan como colaboradores Sinesio Fraga, Xosé Lesta Meis, Rafael Villaseca y Benito Rivadulla (Neira Vilas, 2011: 45-47 y 64).

Estas dos publicaciones periódicas -muy especialmente Eco de Galicia-también fueron importantes para la edición del libro gallego, pues en sus páginas publicaron sus obras destacados autores de la emigración gallega en Cuba y de la propia Galicia, que encontraron en estas publicaciones un medio de expresión. Por lo que toca a los autores emigrados debemos destacar la figura de Xosé Lesta Meis (1887-1930) que mantuvo en Eco de Galicia la sección «De mi tierra» entre 1925 y 1930, donde se ocupaba de la actualidad política, cultural y literaria de la Galicia del momento. En esta revista publicó «Unha páxina de Estebo» (Eco de Galicia, no 325, 1927), un adelanto de 
lo que sería su novela Estebo (1927), que vería la luz en la colección de novelas "Lar», que se publicaba en A Coruña. Por lo que respecta a los autores que desde Galicia publicaron en Eco de Galicia podemos destacar al periodista Avelino Rodríguez Elías (1872-1958), que dio a conocer en esta revista textos como "O albañil d'o convento» (no 159, enero 1922), "O amor propio d'unha rapaza» (no 184, febrero de 1923), «¡Agora si qu'eres un home!» (no 362, octubre 1930).

Fernández Doallo fue, en 1927, elegido como presidente de la sociedad Comité ProCasa Curros Enríquez. De la misma forma ocupó el cargo de consiliario suplente de la directiva de la Sociedad de Beneficencia de Naturales de Galicia (decana de las entidades gallegas de la Habana) para el año social 1929/1930; y, en enero de 1930, el de consiliario de esta asociación por un periodo de dos años. También en 1931 fue nombrado delegado de Beneficencia Gallega en el Comité de Auxilio «Pro Inmigrantes Españoles». En el desempeño de esta misión tuvo una fuerte polémica con el cónsul general de España en La Habana, que terminó en los tribunales. En 1932 fue elegido como vicesecretario de la Beneficencia Gallega. En abril de 1934 pasó a ocupar, de forma interina, la vicepresidencia segunda de esta institución, por renuncia del titular. En la renovación de 1935 siguió ocupando el puesto de vicepresidente segundo. Fernández Doallo tuvo una destacada actuación como directivo de la sociedad Unión Orensana, y fue elegido en 1934 como vicepresidente de la misma.

En 1935 realizó un viaje a España para recuperarse de la enfermedad que padecía pero, al no superar esa dolencia, falleció en ese mismo año. En Manuel Fernández Doallo se personifican las aportaciones de la emigración a la cultura gallega en general y al mundo de la edición y el periodismo en particular.

Desde 1919 colaboró en Eco de Galicia y Heraldo de Galicia Francisco "Fuco" Gómez (1895-1972), promotor también de varias publicaciones periódicas gallegas en La Habana. Hábil polemista, Fuco Gómez fue un prolífico escritor, destacando siempre por sus ideas nacionalistas favorables a la independencia de Galicia. Así, dirigió Nós y más tarde Terra Gallega, boletines de la "Irmandade Nazonalista Galega". En 1941 fundó -y prácticamente redactó en solitario- el periódico Patria Galega, publicación que editó hasta finales de 1960 (Diéguez Cequiel, 2015: 226).

El relato de la revista Eco de Galicia nos conduce, de igual manera, al destacado papel de la mujer en el periodismo gallego en Cuba. Debemos, pues, mencionar a Mercedes Vieito Bouza, nacida en La Habana el 11 de febrero de 1887, hija de emigrantes gallegos naturales de As Somozas (A Coruña). Con una sólida formación académica, Mercedes Vieito comenzó a colaborar en 1903 con la revista Galicia ${ }^{16}$, encargándose

\footnotetext{
${ }^{16}$ Podemos afirmar que la revista Galicia fue una de las publicaciones más longevas de la prensa gallega editada en Cuba. Su primer número apareció el 25 de julio de 1902, registrándose su duración hasta 1930. Dirigida por Vicente López Veiga, se trataba de una revista ilustrada de información general:
} 
de la sección "Rápidas». Sin embargo, sería en Eco de Galicia donde obtuvo sus mayores éxitos literarios y periodísticos, encargándose también de la dirección de esta revista entre 1934 y $1936^{17}$. Vieito Bouza representó a la perfección la biografía de la periodista gallega en Cuba, una ocupación no profesionalizada que se debía compaginar con otros trabajos. De esta forma, Mercedes Vieto se dedicó a la educación. Fundó la escuela "La Aurora» en el barrio habanero de Luyanó, dedicada a la enseñanza primaria de niños y de niñas (Enjamio Expósito, 2010: 144-158).

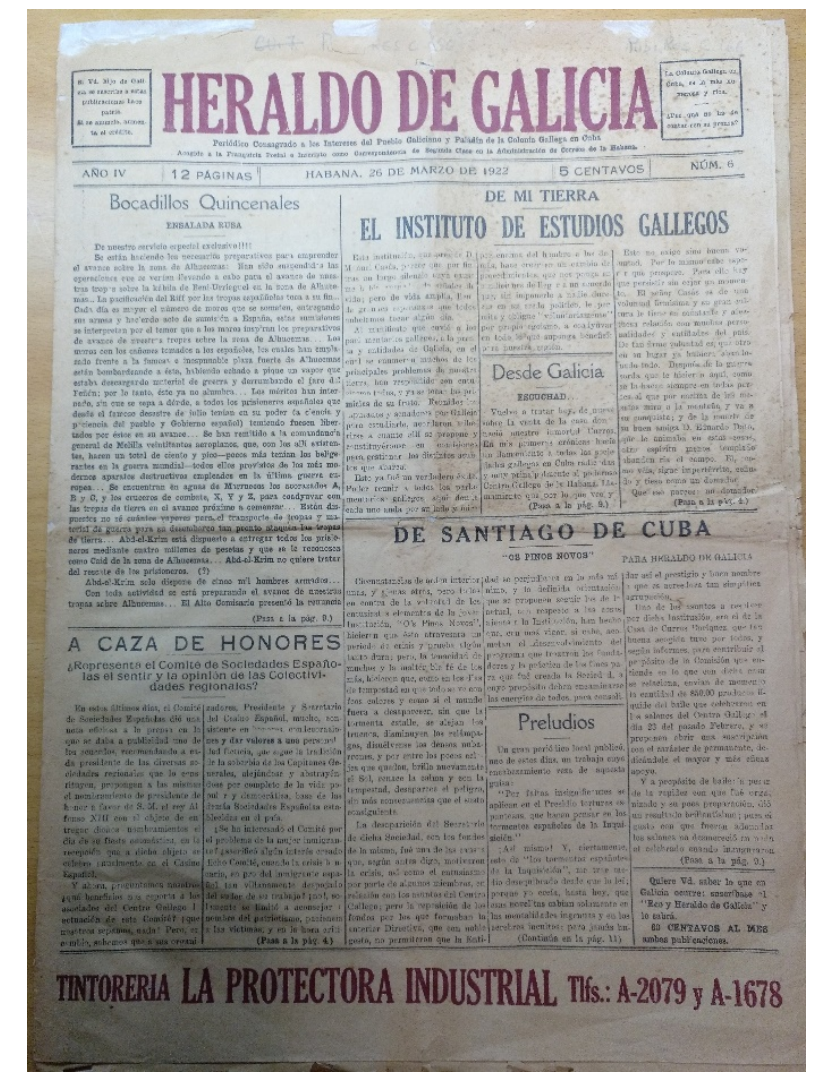

Imagen VI: Heraldo de Galicia (La Habana). Fuente: autor

\section{Conclusiones}

A lo largo de las primeras décadas del siglo XX la emigración formó parte del paisaje cotidiano de Galicia. Sin embargo, lejos de ser realidades separadas y sin contacto, la tierra gallega y sus emigrantes mantuvieron un alto grado de comunicación. La prensa

noticias de la colectividad gallega y sus instituciones, así como un registro de la actualidad procedente de Galicia. (Neira Vilas, 2011: 56-59).

${ }^{17}$ En la nómina de periodistas gallegas en Cuba debemos recordar a Virginia Auber Noya (1821-1897). Bajo el pseudónimo de Felicia publicó sus colaboraciones en los principales diarios de La Habana, sobre todo en el Diario de la Marina, periódico en el que también aparecieron sus novelas por entregas. 
editada en América contribuyó, sin duda, a que esto fuera así. Los periódicos americanos informaron a ambas orillas del océano, del mismo modo que fueron vehículo necesario para el viaje de ideas y causas políticas, es decir, un elemento de influencia de primera mano.

La prensa gallega editada en la emigración cumplió, así, el doble objetivo de mantener a los emigrantes informados de los problemas de la colectividad y de lo que sucedía en Galicia. Ahora bien, debemos afirmar que a través de los periódicos mencionados en este trabajo, la mayoría de los cuales también llegaban a Galicia, los periodistas emigrados pretendían influir en la política gallega del momento, en la mayoría de las ocasiones en clave galleguista y de lucha contra el caciquismo del régimen de la Restauración. Es en este sentido en el que la prensa emigrada cumplió su misión de intermediadora entre dos continentes.

Sin embargo, el deseo de los emigrantes de influir en el devenir político del país natal fue todavía más claro cuando comenzaron a financiar medios de comunicación propios en Galicia. Aquí el ejemplo más claro lo tenemos en el periódico El Emigrado, creado en A Estrada (Pontevedra) y financiado por emigrantes naturales de este ayuntamiento en Cuba y Argentina. El primer número de este medio apareció el 15 de septiembre de 1920, perviviendo hasta 1940. El Emigrado constituye el ejemplo ideal de las tentativas de los emigrantes por influir en la política gallega; téngase en cuenta que, siguiendo a Justo Beramendi, en 1927 este periódico tiraba la considerable cifra de 2.000 ejemplares (Beramendi, 2007: 687).

En otras ocasiones, para favorecer la obtención de noticias de la tierra natal, y mantenerse permanentemente informados, los emigrantes financiaron medios de comunicación ya existentes. Así, en 1909 los emigrantes de O Valadouro (Lugo) en Cuba favorecieron una segunda época de la revista Brisas del Oro, que se publicaba en su municipio natal y que les llevaría noticias -iy fotografías!- de su tierra:

En breve reaparecerá la revista Brisas del Oro, debido a las reiteradas peticiones de los residentes en América.

Esta publicación la tomó bajo su protección la sociedad cubana "El Valle de Oro" recomendándola a todos los asociados, que serán suscriptores ${ }^{18}$.

\footnotetext{
${ }^{18}$ La Idea Moderna, Lugo, 25 de noviembre de 1909.
} 


\section{Referencias bibliográficas}

ARCA CALDAS, O. (1997): Waldo Álvarez Insua: estradense, emigrante, escritor, A Estrada, Asociación Fillos e Amigos da Estrada.

BERAMENDI GONZÁLEZ, J. (2007): De provincia a nación. Historia do galeguismo político, Vigo, Edicións Xerais de Galicia.

BLANCO CAMPAÑA, X.L. (1995): Prensa e radio na Galicia exterior, Santiago de Compostela, Xunta de Galicia.

BUGALLAL Y MARCHESI, J. (1959): Isidoro Araujo de Lira. Vocación y sacrificio de un periodista gallego universal, conferencia pronunciada en el "Liceo Artístico e Instructivo» de Bouzas, el día 12 de diciembre de 1958, Vigo, Faro de Vigo.

BARREIRO FERNÁNDEZ, X.R. (2012): “Manuel Castro López, un intelectual e un emigrante da utopía", estudio introductorio a la edición facsimilar del Almanaque Gallego, Santiago de Compostela, Consello da Cultura Galega, pp. 1132.

DÍAZ, H. M. (2007): Historia de la Federación de Sociedades Gallegas: identidades políticas y prácticas militantes, Buenos Aires, Fundación Sotelo Blanco-Biblos.

DIÉGUEZ CEQUIEL, U.B. (2015): Nacionalismo galego aquén e alén mar. Desarticulación, resistencia e rearticulación (1936-1975), Santiago de Compostela, Edicións Laiovento.

ENJAMIO EXPÓSITO, M. S. (2010): “Mercedes Vieito Bouza: ¿cubana ou galega?, en Aneiros Díaz, R. et. al. (2010): Xornalistas con opinión II: 20 biografías, Santiago de Compostela, Consello da Cultura Galega, pp. 144-158.

NEIRA VILAS, X. (1994): Memoria da emigración I, Sada (A Coruña), Ediciós do Castro.

- (2011): A prensa galega en Cuba, Santiago de Compostela, Xunta de Galicia (1a edición Ediciós do Castro, 1985).

NÚÑEZ SEIXAS, X.M. (1998): Emigrantes, caciques e indianos. O influxo sociopolítico da emigración transoceánica en Galicia (1900-1930), Vigo, Edicións Xerais de Galicia.

- (2010): “Periodismo, patriotismo «regional» y estrategias de liderazgo: Fortunato Cruces, José R. Lence y los gallegos de Buenos Aires (1900-1936)", en García Sebastiani, M. (dir.) (2010), Patriotas entre naciones. Élites emigrantes españolas en Argentina (1870-1940), Madrid, Editorial Complutense, pp. 273305.

- (2014): Las patrias ausentes. Estudio sobre historia y memoria de las migraciones ibéricas (1830-1960), Oviedo, Genueve Ediciones. 
PEÑA SAAVEDRA, V. (dir.) (1998): Repertorio da prensa galega da emigración, Santiago de Compostela, Consello da Cultura Galega.

REGUEIRO, N. (2006): Introducción a la edición facsimilar de A Gaita Gallega, Santiago de Compostela, Xunta de Galicia, pp. 45-104.

SANTOS GAYOSO, E. (1990): Historia de la prensa gallega (1800-1986), Sada (A Coruña), Ediciós do Castro.

VILANOVA RODRÍGUEZ, A. (1966): Los gallegos en la Argentina, Buenos Aires, Ediciones Galicia (2 volúmenes).

VILLARES, R. / MARCELINO, F. (1996): Historia da emigración galega a América, Santiago de Compostela, Xunta de Galicia.

VILLARES, R. (1997): Figuras da nación, Vigo, Edicións Xerais de Galicia.

- (2017): Identidade e afectos patrios, Vigo, Editorial Galaxia.

VIVEIRO MOGO, P. (2010): “La reivindicación de Galicia en la República Argentina: algunas notas sobre la movilización política de los emigrantes gallegos (18901936), en Cuadernos de Investigación Histórica, no 27, 2010, pp. 383-419. 